\title{
INCLUSÃO DIGITAL E EDUCAÇÃO: UMA LENTA CONEXÃO
}

\author{
DIGITAL INCLUSION AND EDUCATION: A SLOW CONNECTION \\ INCLUSIÓN DIGITAL Y EDUCACIÓN: UNA LENTA CONEXIÓN
}

Isabel

Domingues*

*Mestre em Gestão e

Desenvolvimento da Educação

Profissional pelo Centro Estadual de Educação Tecnológica Paula

Souza (CEETEPS). Especialista em Administração de Marketing pela Universidade Paulista e em Docência da Educação

Profissional pelo Centro Universitário Senac. Bacharel em Comunicação Social pela Universidade de Mogi das Cruzes. Docente do Senac. São Paulo, São Paulo, Brasil. E-mail: designer.idg@gmail.com Recebido para publicação em: 7.4.2017

Aprovado em 6.3.2018

\section{Resumo}

A mediação do professor para o acesso dos alunos à tecnologia é a questão deste trabalho. Em um mundo ainda cheio de pontos de sombra tecnológicos, qual o papel da escola e da sociedade para dirimir as diferenças no mundo virtual, de forma que uma parcela cada vez maior da sociedade consiga se beneficiar do uso das Tecnologias da Informação e Comunicação (TIC) de forma democrática e igualitária? O objetivo é problematizar como a educação está trabalhando as novas tecnologias para o ensino e a construção de uma nova sociedade.

Palavras-chave: Inclusão digital. Tecnologia da informação e comunicação. Educação do futuro.

\section{Abstract}

The teacher's mediation for students' access to technology is the concern of this work. In a world still full of technological shadow spots, what is the role of the school and society in bridging differences in the virtual world, so that a growing share of society could benefit from the use of Information and Communication Technologies (ICT) in a democratic and egalitarian way? The goal is to discuss how education is shaping the new technologies for teaching and building a new society.

Keywords: Digital inclusion. Information and communication technology. Education of the future.

\section{Resumen}

La mediación del profesor para el acceso de los alumnos a la tecnología es el tema de este trabajo. En un mundo aún lleno de 
puntos de sombra tecnológicos, ¿cuál es el papel de la escuela y de la sociedad para dirimir las diferencias en el mundo virtual, de modo que una parte cada vez mayor de la sociedad consiga beneficiarse del uso de las Tecnologías de la Información y la Comunicación (TICs) de forma democrática e igualitaria? El objetivo es problematizar cómo la educación está trabajando en las nuevas tecnologías para la enseñanza y la construcción de una nueva sociedad.

Palabras clave: Inclusión digital. Tecnología de la información y comunicación. Educación del futuro.

\section{Introdução}

Hoje em dia, há o questionamento sobre se a educação vem acompanhando os movimentos tecnológicos da atualidade e em qual proporção essa evolução vem ocorrendo. Estariam os professores, currículos e escolas preparados para as inovações que as tecnologias da informação e comunicação vêm proporcionando à sociedade da informação? Em contraponto a um mundo em movimento, onde a tela do computador é sinônimo de resposta automática para todas as dúvidas, há uma escola que confina seus estudantes não somente dentro de suas paredes, mas também dificultando a ação investigativa por não possuírem habilidades para extrair o que há de melhor no seu uso.

Atualmente, quando está em pauta o tema "direito à educação", pensa-se em inclusão social, afinal, a mesma se traduz em um processo social pelo qual os indivíduos se adaptam para agregar as pessoas que foram excluídas dessa dinâmica por terem sido destituídas de seus direitos básicos.

Essa mesma lógica pode ser seguida com a exclusão digital, pois, nesse caso, deixa-se à margem da informação (em especial, do uso das tecnologias da informação e comunicação e, mais recentemente, das relações em rede), um contingente que poderia se beneficiar da mesma e, por não o fazer, encontra-se em desvantagem, o que pode aumentar as diferenças sociais.

Proporcionar condições para que pessoas de todos os credos, cores, raças, orientações sexuais e condições financeiras tenham garantidos seus direitos de acesso aos benefícios sociais com equidade e justiça garante melhor condição de aceitação, identidade e convivência em sociedade.

Neste trabalho, deseja-se compreender o conceito de inclusão e exclusão digital, sua dinâmica social na atualidade, as conexões e congruências com a educação e seus atores, compreendendo os impactos de um sobre o outro. 
Quando se comparam os conceitos de inclusão social e inclusão digital (como antagonismo, tem-se a exclusão digital, também chamada de "infoexclusão"), apresentados na literatura sobre o assunto, constata-se que há grandes congruências entre eles. Para exemplificar, ver o Quadro 1.

\section{Quadro 1 - Inclusão digital x inclusão social}

Inclusão digital: é, como ponto de partida, o acesso à informação que está nos meios digitais e, como ponto de chegada, a assimilação da informação e sua reelaboração em novo conhecimento, tendo como consequência desejável a melhoria da qualidade de vida das pessoas (SILVA et al., 2005)
Inclusão social: é a forma pela qual a sociedade se adapta para poder incluir, em seus sistemas sociais gerais, pessoas que foram excluídas desses sistemas e, simultaneamente, essas pessoas também se preparam para assumir seus papéis na sociedade (SASSAKI, 1997).

Fonte: Elaborado pela autora.

Quando se diz que a inclusão social "prepara pessoas para assumir seu papel na sociedade", não se pode dissociar esse elemento participativo da relação de se ter acesso aos benefícios da vida em sociedade. Mas ao se pensar que a inserção na sociedade da informação pode ser uma prerrogativa da vida em sociedade, percebe-se não ser exagero considerar a exclusão digital também uma exclusão social. Se há algo em comum entre exclusos sociais e digitais, o que seria? Seria a classe social desprovida de recursos financeiros? Seria sua cor, religião, gênero, orientação sexual ou nada disso? O fato é que um sujeito preparado para assumir seu papel na sociedade só o faz mediante o uso do pensamento reflexivo, o que pode ser potencializado pela sua inclusão digital, a qual pode colaborar na "assimilação da informação e sua reelaboração em novo conhecimento".

Por isso, os termos em contraponto apresentam a possibilidade de existir um grupo de indivíduos que não está incluso nos benefícios da sociedade (exclusão social) da informação (exclusão digital) e, portanto, não gozam de uma série de prerrogativas sociais que esses benefícios pressupõem, e isso acaba virando um ciclo sem fim: a exclusão digital fomenta as diferenças socioeconômicas e as diferenças socioeconômicas fomentam a exclusão digital. E nesse ciclo, o que é causa e o que é consequência?

Para Lemos (2011), programas de inclusão digital devem pensar a formação global do indivíduo para a inclusão social, e não somente colocá-lo em contato com o computador. Isso, porém, só ocorre quando há projetos e políticas públicas que inter-relacionam educação, cultura, sociedade e tecnologia de forma que tudo isso possa fazer sentido em conjunto. Nesse caso, o autor ainda acrescenta que se conhece por projetos de inclusão social aqueles frutos de trabalho educativo e de 
políticas públicas que objetivam dar oportunidade a uma parcela da população excluída não somente do uso, mas dos benefícios da sociedade da informação. Ressalta também que quando se fala em inclusão digital, deve-se levar em conta os quatro capitais da inteligência coletiva: capital social, cultural, técnico e intelectual, conforme aponta o Quadro 2.

\section{Quadro 2 - Os quatro capitais da inteligência coletiva}

\begin{tabular}{|l|l|}
\hline Tipo de capital & Característica \\
\hline Capital social & $\begin{array}{l}\text { Valoriza a dimensão da identidade e comunidade, as ações políticas e } \\
\text { sociais. }\end{array}$ \\
\hline Capital cultural & Caracterizado pelos bens simbólicos de grupos e sua história. \\
\hline Capital técnico & Tem foco na força da ação e da comunicação. \\
\hline Capital intelectual & $\begin{array}{l}\text { É aquele referente à formação da pessoa, do crescimento da } \\
\text { aprendizagem e da troca de conhecimentos e saberes. }\end{array}$ \\
\hline
\end{tabular}

Fonte: Lévy (1998).

Por isso, Lemos (2011) acrescenta que incluir é, antes de mais nada, possibilitar o crescimento desses capitais, o que já se percebe traz desenvolvimento e crescimento a seus participantes, seja um país, seja um indivíduo, seja uma instituição. Ele aponta que o maior desafio da inclusão cidadã na cultura digital é fazer com que os indivíduos produzam conteúdos próprios e os distribuam livremente, mas podendo manter seus dados pessoais, privacidade e anonimato. Para ele, os projetos de inclusão digital devem fazer crescer os capitais técnico, social, intelectual e cultural e a inclusão pressupõe autonomia, liberdade e crítica.

No caso específico dos indivíduos que desconhecem as possibilidades advindas da sociedade da informação, nesta nova era, ficar aquém no que se refere ao engajamento digital pode acarretar atrasos ou mesmo estagnação nas possibilidades de inserção no mercado de trabalho, nas interações pessoais e acadêmicas, e principalmente, excluir o sujeito de um circuito de conhecimento global que pode ser fundamental para a sobrevivência das relações na sociedade contemporânea.

Esse engajamento digital está muito ligado ao uso das TIC. A expansão das TIC tem estimulado a produtividade e o crescimento econômico dos países, inclusive encurtando o ciclo de vida dos produtos, globalizando os mercados, fazendo as distâncias terem menos importância e alterando significativamente o modo como as pessoas vivem e trabalham, e por que não dizer, relacionam-se.

Se há o ideário de que o conhecimento é emancipatório, propiciar caminhos para essa emancipação nos dias de hoje percorre as trilhas da inclusão digital, afinal, é assim que as informações serão propagadas e os conhecimentos novos, criados. 
Aqui entende-se informação e conhecimento conforme a conceituação de Monteil (1985), na qual a informação é tratada como um agrupamento de dados exteriores ao sujeito e pode ser armazenada e estocada (tem um caráter objetivo), enquanto o conhecimento é visto como o resultado daquilo que é experimentado pelo sujeito, isto é, ligado à sua atividade (tem um caráter subjetivo). O mesmo autor então traz a ideia do saber como algo que está "sob a primazia da objetividade", como a informação, é algo de que o sujeito se apropria. Ele preconiza que o saber é produzido pelo sujeito confrontado a outros sujeitos.

Quando se fala em emancipação não se pode deixar de citar Adorno (1995), o qual afirma que a educação tem a finalidade de promover a emancipação do pensamento humano. No entanto, deve-se entender que quando essa teoria foi idealizada por Theodor Adorno, a relação de emancipação estava vinculada à

0 que se dizer das TIC, que já se afirmam como uma das indústrias que mais crescem mundialmente? barbárie nazista e à indústria cultural, isto é, era uma crítica ferrenha aos processos pré-estabelecidos advindos da mesma, na disseminação de uma cultura de massa, usada inclusive na disseminação dos ideais nazistas, o que prejudicava a ação autônoma do homem. A educação tinha o papel então de reverter esses processos, e pela reflexão, trazer o homem à emancipação e autonomia de pensamento, o que aponta também como algo difícil, pois a própria escola tem seus próprios formatos ideológicos.

Hoje em dia, contudo, há o antagonismo das possibilidades, isto é, as TIC representam uma grande possibilidade para disseminação de conhecimentos, e portanto podem ser utilizadas de forma profícua com objetivos educacionais, mas também são uma das maiores fontes de articulações advindas da indústria cultural, pela qual já se reafirma como um dos maiores meios de comunicação de massa, vistos os números tão grandiosos revelados pelas redes sociais na utilização de novas tecnologias, meios, formatos, atores e mensagens.

Se o medo de os meios de comunicação de massa "pasteurizarem" as pessoas, ocorrido na década de 1950, já mobilizou a realização de estudos no âmbito da sociologia, psicologia e antropologia, o que se dirá de um meio altamente mutante, que se adequa à sua audiência e tem a capacidade de aprender com ela novos hábitos e costumes? O que se dizer das TIC, que já se afirmam como uma das indústrias que mais crescem mundialmente?

Talvez por isso, hoje em dia, quando se fala em tecnologia, apesar de errôneo, já se traduz no imaginário popular: TIC. Mas quando se trata de inclusão digital e educação, incentiva-se os primeiros passos para qualquer um que deseje entrar no espaço da cibercultura, ou que, mesmo grosseiramente ou com pouco letramento digital, pretendem conectar-se nesta rede infinita de possibilidades que coloca o ser humano em contato com outras dimensões e possibilidades para "tornar-se" e identificar-se. 


\section{Exclusão digital}

Atualmente, a população mundial já passa de 7,3 bilhões de habitantes, segundo o relatório da Organização das Nações Unidas para a Educação, a Ciência e a Cultura (POPULAÇÃO..., 2015). O mesmo relatório identifica que, até 2100, este número aumentará cerca de $53 \%$. No fim de 2013, a ONU também identificava que cerca de 4,4 bilhões de habitantes não tinham acesso sequer à internet. Assim, consegue-se entender o quanto ainda é preciso realizar para que o mundo consiga alcançar a equidade digital.

Pierre Lévy (1998) já pontuava desde a década de 1980 que toda tecnologia nova cria seus próprios excluídos. Isto não é uma afirmação que apoia a existência dos excluídos, mas sim, demonstra que todo processo para implantação de novas tecnologias inicia-se com pessoas que não as detêm, o que não significa que não possam se tornar comuns depois de algum tempo. Esse processo lento, se puder levar em conta o próprio crescimento tecnológico, remonta ao acesso a ferramentas tecnológicas que se popularizaram, mas que também ainda não são unanimidades: energia elétrica pode ser um bom exemplo. Apesar de a descoberta ter ocorrido em meados do século 18, ainda há, segundo os relatórios do Ano Internacional da Luz (UNESCO, 2015), cerca de 1,5 bilhão de pessoas sem acesso a esse benefício, o que, em suas consequências, já se relaciona a uma série de carências em várias esferas da vida, inclusive à exclusão digital, por exemplo.

No caso da exclusão digital e das novas tecnologias, em especial advindas do desenvolvimento das TIC, o que se repara é uma imensa lacuna entre os inclusos e os exclusos, causando uma grande discrepância, que se amplia quando se fala em relações sociais, educacionais e econômicas, o que acarreta grandes prejuízos no crescimento das nações das quais faz parte esse contingente, dificultando, inclusive, seu desenvolvimento, o que acaba por desequilibrar, por escala, a geopolítica mundial.

Para fins de exemplo, segundo matéria de 2011 do site Tecmundo, pesquisadores da Universidade da Califórnia estimaram que as informações produzidas entre 1986 e 2007 eram equivalentes a 296 exabytes. Para esclarecer melhor o que isso significa, um DVD comum grava 4,7 gigabytes, e se fosse usado para armazenar todas essas informações, daria uma pilha com mais de 404 bilhões de discos, algo que ultrapassaria, de acordo com a matéria, a órbita da lua (ver o Quadro 3):

\section{Quadro 3 - Equivalências}

\begin{tabular}{|c|c|}
\hline 1024 gigabyte & 1 terabyte \\
\hline 1024 terabyte & 1 petabyte \\
\hline 1024 petabyte & 1 exabyte \\
\hline
\end{tabular}

Fonte: Smaal (2011) 
Ao se levar em conta que, em 2007, ainda não se tinha a cultura arraigada do uso do smartphone para conexão e nem mesmo a advento do WhatsApp, criado somente em 2009, imagina-se quão defasados já estão esses dados, e como a geração "compartilhamento de informações" já exacerbou tudo o que foi apresentado. Prova disso foi o crescimento das plataformas em cloud, o que denota a necessidade de os usuários das tecnologias da informação tê-las em fácil acesso e a qualquer tempo.

É evidente que nem todas essas informações produzidas são utilizáveis, úteis ou mesmo acessíveis a todos. Também pode-se contrapor que nenhum ser humano tem condições de processar esse número de informações em seu cérebro, por isso é indiferente se falar em números absolutos de forma pontual, mas o que se espera demonstrar é a grandiosidade de produção, do tráfego e armazenamento de informações (não se fala aqui de conhecimentos ou saberes), que uma parcela tão grande do mundo sequer sabe que existe, sequer tem o direito a saber e mesmo que saiba da existência ou tenha o direito de acessar, não tem oportunidade de fazê-lo por falta de condições físicas, culturais, religiosas, econômicas ou sociais.

Dirimir esse processo para combater suas consequências já citadas é função dos governos e da sociedade, o que resultará em uma abertura de fronteiras (virtuais) que poderão colaborar para que esse indivíduo perceba, no mundo, múltiplos caminhos para "se tornar", imaginando que outros também já o fizeram e enxergando a possibilidade de também o fazer.

\section{Dimensões da inclusão digital}

Para se estabelecer uma análise mais linear, deve-se refletir sobre a inclusão digital em quatro dimensões: da sociedade; da escola; do professor e do indivíduo. Essas dimensões foram escolhidas arbitrariamente em função dos objetivos propostos, o que não esgota as possibilidades e dimensões que podem ser exploradas na discussão do mesmo tema.

\subsection{A inclusão digital da sociedade}

Pode-se ter uma ideia da penetração das TIC na sociedade, em especial, quando se refere à expansão da banda larga no mundo. Este processo, além de possibilitar conexões mais rápidas e com maior qualidade de transmissão de dados, também possibilita o desenvolvimento de novas tecnologias, soluções, aplicativos, entre outros, que dependem dessas conexões e transmissões para serem viabilizados. Lembrando que sendo a 4G, isto é a $4^{a}$ geração de telefonia móvel, já uma realidade comum em muitos centros urbanos, essa conexão pode ocorrer em um tablet, notebook e, também em franca expansão, um smartphone.

Um dos fatores que seguram o crescimento da banda larga em grande escala ainda são seus preços, no entanto, é uma situação que está se modificando. Segundo o relatório UIT¹ (NAÇÕES UNIDAS, 2013), entre 2008 e 2012, em mais de 160 países, 
os preços fixos da banda larga caíram $82 \%$. A maior queda ocorreu nos países em desenvolvimento, onde os preços de banda larga fixa caíram 30\% a cada ano entre 2008 e 2011. Isso demonstra não somente uma tendência, mas também uma perspectiva de crescimento que pode ser diretamente proporcional à diminuição dos preços para acesso, o que tornará a rede mundial muito mais democrática em suas conexões. Neste caso, os pontos de Wi-Fi livres, subsidiados pelos governos ou mesmo pela iniciativa privada, com o intuito de atrair mais clientes, interessados em bons serviços, atendimento e conectividade, podem se ampliar ou mesmo demandar novas configurações para melhoria de acesso.

Muito ainda há que se realizar em termos de infraestrutura e desenvolvimento de produtos que propiciem uma grande massa conectada
O Erickson Mobility Report de junho de 2015 relata que nos próximos cinco anos o acesso à banda larga mais que duplicará, chegando a 7,7 bilhões, e que serão os smartphones que impulsionarão esse crescimento, passando, nesse período, a mais de 6 bilhões de usuários conectados. Diz também que Ásia, Oriente Médio e África deverão alavancar seus acessos. Com a expectativa do $5 \mathrm{G}$ para 2020, ainda relata novos usos e possibilidades para a rede móvel que poderão ser implementados. Nos próximos cinco anos, a perspectiva é que $90 \%$ da população mundial tenha cobertura de banda larga móvel. Segundo o estudo, o número de assinantes chegará a superar o de habitantes e a tendência mostra que nos próximos cinco anos $90 \%$ da população mundial acima de seis anos de idade terá um celular com acesso à internet.

Esses números são apenas indicativos do futuro, de acordo com o crescimento do mercado e suas projeções, mas o que de fato interessa analisar é o prognóstico que aponta os caminhos de crescimento das tecnologias voltadas a telecomunicações e consequentemente, das TIC, o que acaba por impulsionar todas as instituições e organizações que fazem uso dela em seu percurso diário. Os números do relatório mostram também como ainda há muito a crescer e ser implementado, muito embora ainda exista um grande contingente que não tem acesso nem a um computador com rede discada, bem como os interesses comerciais para que essa expansão ocorra e seja significativa em termos de desenvolvimentos de novos mercados e, consequentemente, financeiros. Essas prerrogativas existem muito em função das grandes áreas de sombras mundiais que, a longo prazo, estabelecem a propensão a um crescimento, uma vez que se encontram em situação de defasagem em relação a outras regiões. São bons exemplos a África e o Oriente Médio. Como isso ocorrerá ainda não se sabe, o que se sabe é que governos têm se mantido atentos ao desenvolvimento tecnológico e seus impactos em suas economias.

Muito ainda há que se realizar em termos de infraestrutura e desenvolvimento de produtos que propiciem uma grande massa conectada, com preços muito competitivos e, de preferência, subsidiados pelos governos; todavia esse é um processo real e que vem se tornando um fenômeno social com aspectos positivos e negativos que não podem ser ignorados pelas instituições educacionais nem pela sociedade 
como um todo. Neste contexto, a sociedade (e as escolas) devem se adaptar e se relacionar com a nova era, de forma a propiciar aos cidadãos acesso reflexivo e participação ativa em todo esse processo.

Ignorar os caminhos que estão se formando tendo como base as novas tecnologias da informação e lembrando, inclusive, que muitas oportunidades ainda estão por vir até pelos inovadores usos e funções que virão com o advento da $5 \mathrm{G}$ e de outras tecnologias em desenvolvimento, é mostrar-se não somente "refratário" às mudanças, mas também míope socialmente e isso não somente compromete a adaptação das novas gerações às novas demandas sociais, bem como retarda o progresso e o aproveitamento das possibilidades que o desenvolvimento tecnológico pode propiciar à sociedade atualmente e no futuro.

\subsection{A inclusão digital da escola}

Segundo o filósofo clássico Aristóteles: "Nada está no intelecto sem antes ter passado pelos sentidos". Dentro dessa frase encontra-se muito material para reflexão, em especial para as escolas na atualidade. De fato, quando se pensa no papel da escola e na sua função de levar o indivíduo a "tornar-se" (identificar-se) na sociedade, a ser um espaço de desenvolvimento e aprendizagem, não se pode minimizar o fato de esse espaço estar fadado à circulação de conhecimentos. Mas como essa escola está se formatando para agir nos sentidos de seus alunos? Em um mundo em que todos os sentidos das crianças ganham e perdem funções em contraponto às tecnologias desenvolvidas, como a escola tem se preparado para essas novas demandas?

Walter Ong (1998, p. 78), intelectual e importante pesquisador do letramento e da oralidade, publicou: "as tecnologias não são mera ajuda exterior, mas transformações interiores de consciência, ainda mais quando afetam a palavra". Apesar de controversa para a época, essa afirmação bastante pertinente denota a estrita relação entre o uso das tecnologias (em especial as TIC), as conexões mentais e a forma com que essa pessoa se relacionará e se comunicará com o mundo. Essa forma de apropriação da tecnologia no dia a dia é que impactará como o sujeito pensará a resolução de seus problemas, e, consequentemente, isso acaba por criar conexões completamente novas em sua mente. Um bom exemplo ainda é o homem antes e depois da popularização da energia elétrica. Seus hábitos, costumes e desenvolvimento foram largamente afetados pela nova tecnologia disponível. Ainda nos dias de hoje, o acesso à energia elétrica muda a vida das pessoas. Como as tecnologias da informação e comunicação, ou mesmo o advento da internet não o faria?

Em uma tentativa de colocar suas instituições afinadas com os avanços da tecnologia, governos em todo o mundo distribuíram equipamentos nas escolas. A ideia era colocar crianças e jovens não somente em contato com as novas tecnologias, mas também propiciar novas formas e fontes de pesquisa, novos processos para se realizar antigas tarefas, formas alternativas para se comunicar com outras 
pessoas, culturas, hábitos, entre outros, mas o que talvez não tenha se imaginado era que apesar de o acesso ao computador ser um avanço em muitas comunidades, apenas a sua existência não torna esse sujeito "participante da economia da informação e nem da sociedade em rede e essa participação, além de requerer acesso físico ao computador e conectividade, também exige acesso à habilidade e ao conhecimento, ao conteúdo e à língua [...] para ser capaz de utilizar as TIC para finalidade significativa" (WARSCHAUER, 2006 p. 289).

Dessa forma, as escolas devem não somente disponibilizar o meio físico que propicia aos alunos se apossarem de novos conhecimentos, mas fazer com que esse aluno tenha a visão crítica de suas necessidades ao utilizar essa ferramenta, e, mais ainda, explorar as possibilidades que irão colaborar com o desenvolvimento de seus saberes. Isso só poderá ocorrer se a escola se adaptar para receber essas novas demandas com grades curriculares adequadas, espaços multimeios pensados com finalidade pedagógica, programas e aplicativos voltados ao trabalho docente interativo e dinâmico e um docente engajado na causa.

Fugir à tentação de entulhar as escolas com equipamentos que, em geral, são colocados em uma sala sem condições para recebê-los, por pessoas sem condições de manuseá-los, disponível para alunos sem condições de tirar o melhor proveito deles, já virou uma meta em muitos municípios Brasil afora. Iniciativas que trazem à luz a ideia de se utilizar este recurso de forma pragmática, dentro de um processo que inclui o preparo do espaço, dos docentes e dos alunos, parecem cada vez mais fazer parte do projeto de inclusão de muitas escolas. Mas muito mais do que todo esse processo, para a escola ser agente de inclusão, necessariamente, precisará fazer com que esse aluno perceba a utilidade do recurso para seu aprendizado e isso inclui, obrigatoriamente, colocar tanto o recurso tecnológico como sua utilização sistemática, dentro da grade curricular do ensino regular, o que ainda pode ser, especialmente no Brasil, um grande desafio para a educação.

\subsection{A inclusão digital do professor}

Pesquisadores das ciências sociais já colocaram em suas pautas de estudos a inclusão digital entre os aspectos relevantes a serem investigados na sociedade pós-moderna. Seus impactos na vida das pessoas, a médio e longo prazos, podem estar vinculados à forma como essas pessoas se relacionam com os outros, como uma possível estratificação social da cibercultura, com massificações relacionadas ao longo e rápido alcance das informações e com a necessidade cada vez maior de se triar, estratificar e personalizar os tipos, meios e formas de informação, comunicação e acessos desejados pelos indivíduos.

Pode parecer estranho, mas talvez seja essa a mais desafiadora função da nova geração de professores, a de mediador e orientador dessas novas possibilidades para que os sujeitos possam ter autonomia na hora da tomada de decisão, com os critérios relacionados a essa triagem, estratificação e personalização. 
Mas para se ter essa capacidade, o docente precisa se voltar a essa realidade. A tecnologia impulsionou o desenvolvimento de ferramentas e soluções que estão disponíveis e fazem parte da vida de seus alunos. Visto por outro ponto de vista, pode-se inferir que apropriar-se de elementos e formatos que são familiares a esses indivíduos pode tornar a aprendizagem algo mais significativo, pois se utilizaria de conhecimentos prévios dos alunos nas aulas, tornando sua predisposição a aprender maior e um esforço mais natural, o que é preceito básico de teorias educacionais como da aprendizagem significativa de Ausubel².

As novas tecnologias de que se pode lançar mão na educação

pressupõem

um interesse do

docente em atualizar-se

constantemente
Para Moreira (1999), essa predisposição para aprender é uma das condições para que ocorra a aprendizagem significativa, pois a aprendizagem pode ser internalizada, produzindo maior interesse em se aprender.

Para uma prática viva da inclusão digital em sala, além de os alunos terem o recurso físico à disposição, o docente deve incorporar em suas práticas o uso dos recursos tecnológicos disponíveis, experimentando aqueles que mais se adequam às necessidades de seus alunos e praticando uma comunicação cooperativa, para que esse aluno seja também protagonista do processo ensino-aprendizagem.

Outro impacto causado pelas novas tecnologias nesse contexto é a necessidade constante de atualização. Antonio Andrade (2005), professor da Universidade Católica Portuguesa, afırma que a nova sociedade exige do professor formação permanente, pois o conhecimento está cada vez mais efêmero em muitas áreas tecnológicas e científicas. 0 desafio de aprender, do latim ad prendere, dar forma às coisas, dominar o caos, é algo inerente à humanidade. Isso implica a capacidade de desaprender e reaprender em permanência.

Percebe-se que as novas tecnologias de que se pode lançar mão na educação pressupõem um interesse do docente em atualizar-se constantemente e, mais do que isso, uma atitude real de envolvimento no processo, mesmo que isso envolva, muitas vezes, sair de sua "zona de conforto" e expor uma "pseudo" fragilidade (alunos de gerações nativas digitais ou mais envolvidos em tecnologia que o docente, por exemplo) que pode, na verdade, ser usada em favor das relações e das trocas em sala de aula. "Ouvir o aluno" (PODEMOS..., 2005)3 pode ser um bom começo para que essa relação se estabeleça.

A inclusão digital não é só o acesso à tecnologia, mas a apropriação dela na resolução de problemas. Um exemplo é a melhoria dos índices de alfabetização pela compreensão do poder da comunicação eficiente e rápida e isso pode ocorrer utilizando-se as tecnologias como ferramenta e levando o aluno a enxergar este poder. O computador não é um simples recurso pedagógico, mas um equipamento que pode se travestir em muitos outros e ajudar a construir mundos simbólicos (PODEMOS..., 2005) $)^{4}$. 


\subsection{A inclusão digital do indivíduo (aluno)}

Nos grandes centros urbanos ou onde quer que se acesse a internet, já é corriqueira a utilização de mecanismos de busca, plataformas de e-mail, blogs, fóruns, notícias, serviços on-line, sites de compartilhamento de vídeos ou redes sociais, que podem, ao mesmo tempo, realizar o acesso ao mundo digital de acordo com o bel-prazer de seu proprietário. Mesmo os relacionamentos profissionais e amorosos não escaparam da evolução das TIC.

Com muitos sites, plataformas, aplicativos e programas, conectar pessoas nunca foi tão fácil. Segundo a pesquisadora Lucimar G. Araújo (2015, p. 2): "[...] facilitou enormemente o acesso à informação, [...] tornando-se indispensável para a vida moderna [...]". Isso impactou diretamente a economia, pois as relações se dinamizaram e agilizaram, trazendo assim um grande desenvolvimento econômico. Porém, essa agilidade também tem suas consequências, pois ao se falar em dinamismo nos mercados, na vida cotidiana e nas relações (por exemplo, aplicativos que te dão conexão instantânea com as pessoas, por meio dos quais se sabe se a pessoa viu sua mensagem, se não viu, que horas, etc.) também pode-se esperar que a ansiedade se propague cada vez mais, em especial dentro de gerações anteriores aos "nativos digitais".

Termo cada vez mais popular, os nativos digitais são aqueles jovens com menos de 24 anos com experiência on-line de mais de cinco anos, isso de acordo com o modelo desenvolvido pela UIT em 2012, o qual mostrava que 5,2\% da população mundial de cerca de 7 bilhões detinham esse perfil (NAÇÕES UNIDAS, 2013). E, meIhor, o relatório previa que em cinco anos a população nativa dobraria.

Essa ansiedade, como já mencionado, percebe-se na dificuldade que muitos adultos têm em escolher um smartphone, baixar ou manusear arquivos digitais ou até mesmo acessar um simples caixa eletrônico. Por vezes, compartilhar espaços com jovens "tão dinâmicos" ressalta essas deficiências fazendo com que muitos adultos se ressintam desses jovens no tocante a essa intimidade digital. O fato é que algumas gerações têm essa intimidade muito mais resolvida no seu dia a dia.

É característica desta população ser conectada e entusiasta do uso das TIC. Essa população, em crescimento mundialmente, é quem mobilizará as transformações na indústria nas próximas décadas. É uma geração que deve ser ouvida e levada em consideração quando o assunto é tecnologia e inovação nas TIC.

Dentro das salas de aulas, estão procurando ser participantes dos processos de formação de seus conhecimentos, escolhendo e interagindo no que vão aprender, em como vão aprender e por que vão aprender. Questionando, inclusive, sua utilidade no futuro.

Desafio para todo docente apaixonado, as novas gerações demandam um mediador generoso e antenado, que deseje compartilhar seus conhecimentos, aprender a cada dia com as dinâmicas das tecnologias e nas relações em rede e que entenda que sua ação não é final, mas uma ponte para descobertas que podem transcender o que eles mesmos sabem. 


\section{Considerações finais}

Carl Rogers, psicólogo norte-americano, em 1969, já preconizava em uma de suas obras que a finalidade da educação estava em propiciar mecanismos que facilitassem a mudança e a aprendizagem, e essa última é pautada em algumas qualidades de atitudes pertinentes à relação pessoal entre facilitador e aprendiz. Essas correlações entre facilitar a mudança e a aprendizagem e a relação entre aprendize "docente" remete à responsabilidade que a educação tem sobre si no que se refere à inclusão digital.

A fim de propiciar a mudança na sociedade ou nos indivíduos e no ideário de se instaurar um processo genuíno de aprendizagem, com respeito e equidade, as instituições educacionais não podem se esquivar da responsabilidade social que possuem junto a seus alunos.

Hoje em dia, jovens desinteressados permeiam as escolas, não encontrando, muitas vezes, sentido em aprender aquilo que julgam ter à mão quando quiserem (utilizam o Google como fonte de saber), por outro lado, há um contingente que sequer sabe o que é rede, quanto mais o que se pode aprender com ela. A heterogeneidade de conhecimentos e literacia digital nas escolas, em especial nas públicas brasileiras, bem como as diferenças contundentes de recursos tecnológicos dos estudantes em sala de aula, podem dar uma simples dimensão do que se espera ou do que se tem pela frente.

Ao ouvir um profissional em uma sala de professores dizer que a educação só seria inovadora e revolucionária quando um jovem (nativo digital) a abrisse para as novas perspectivas do desenvolvimento tecnológico, não se pode ignorar que os próprios docentes se encontram sem perspectivas quanto aos rumos que o processo de desenvolvimento vem tomando.

Pesquisadores pelo mundo já demonstram grande interesse em preparar as novas gerações para além do uso consciente de seus recursos digitais ou para se aprender de forma autônoma com eles. Tendências apontam que jovens e crianças devem ser preparados para desenvolver com destreza pequenos aplicativos, jogos, enfim, soluções personalizadas para suas necessidades específicas, por meio de sistemas simplificados, que propiciem uma linguagem muito mais linear entre a máquina e o homem.

Conexões em rede já formam grandes mundos virtuais, com leis, lideranças e local (virtual). Vale lembrar que não foi a internet que propiciou a comunicação em rede, pois a mesma existe desde que o homem começou a relacionar-se em grupos e em comunidades. A internet e as tecnologias da comunicação vieram e revolucionaram todos esses processos, colocando tudo em condições muito mais viáveis e flexíveis e adaptando-se às necessidades de seus usuários. Isso acabou por dar novos caminhos e propiciar maior desenvolvimento nas relações em rede, inclusive em níveis globais, o que proporciona a um grande número de pessoas conexão com uma infınita malha de situações e contatos cheia de possibilidades para serem exploradas no universo educacional. 
Tantos caminhos apresentados são apenas simples exemplos do que permeia a nossa sociedade atualmente e no futuro, e sendo um fenômeno social, impacta e impactará a escola e as relações que se apresentarão dentro dela.

Apesar do que vem se apresentando, tudo isso não ocorrerá com a velocidade do próprio desenvolvimento tecnológico, em especial nas escolas públicas. Não se pode esperar, com tal rapidez, políticas que direcionem o ensino para práticas muito mais engajadas na realidade dos jovens e customizadas às suas necessidades e condições, o que seria de grande valia, em especial em um país tão grande e com tanta diversidade como o Brasil. Mas o que se pode estabelecer é que governos, sociedade e cidadãos se engajem no processo de inclusão digital, para que esse percurso seja mais rápido e fácil.

Algo já pode ser feito, iniciando-se nas escolas, com ofertas de novos cursos, equipamentos e facilitadores preparados para as novas demandas e novos perfis de alunos, bem como com o desenvolvimento de projetos que viabilizem a inserção de outros públicos que não têm acesso às tecnologias digitais e seus benefícios, de forma a desenvolver cidadãos mais conscientes de seus direitos, críticos em relação às possibilidades e protagonistas no seu processo de aprendizagem. Em especial, as crianças, além de preparadas para as novas demandas, devem ser orientadas quanto aos perigos desse novo mundo virtual que se abre a ela. Não esquecendo de estabelecer possibilidades de acesso não somente a equipamentos, mas também a orientadores, que façam uma ponte entre a tecnologia, o saber e o sujeito.

Se acontecer dessa forma, pode-se afirmar, como Carl Rogers (1969), que será possível facilitar, por meio da educação, a mudança e a aprendizagem, o que poderá influenciar e até melhorar a relação entre docente e aprendiz e, muito mais do que isso, propiciar que os indivíduos tenham a condição de participar ativamente de uma rede de contatos, conhecimentos e oportunidades que hoje, de alguma forma, por muitas vezes ainda Ihes é tolhida. Isso, no longo prazo, pode retardar o crescimento intelectual, social, cultural e profissional, não somente desses indivíduos, mas em um ciclo, como já evidenciado, de toda uma nação.

\section{Notas}

1 União Internacional de Telecomunicações (UIT).

2 David Paul Ausubel (1918-2008) é um pesquisador norte-americano que afirmava que aquilo que o aprendiz já conhece influencia sua aprendizagem.

${ }^{3}$ Lea da Cruz Fagundes: Doutora em educação e coordenadora do Laboratório de Estudos Cognitivos do Instituto de Psicologia da Universidade Federal do Rio Grande do Sul (UFRG).

${ }^{4}$ Dra. Lea da Cruz Fagundes para Revista Nova Escola. 


\section{Referências}

ADORNO, T. W. Educação e emancipação. Rio de Janeiro: Paz e Terra, 1995.

ANDRADE, A. M. V. Tecnologia da informação na gestão. Porto: Universidade Católica Ed., 2014.

ARAUJO, L. G. C. 0 processo de inclusão digital no Brasil: avanços e lacunas. 2015. Dissertação (Mestrado em Estudos Populacionais e Pesquisas Sociais) Escola Nacional de Ciências Estatísticas, IBGE, Rio de Janeiro, 2015.

BARRETO, L. F. B. P. M. Uma análise da divisão digital no Brasil através da aplicação da aprendizagem de redes bayesianas. 2012. Dissertação (Mestrado em Administração) - Faculdade de Economia, Administração e Contabilidade, Universidade de São Paulo, São Paulo, 2012. Disponível em: <http://www.teses. usp.br/teses/disponiveis/12/12139/tde-18022013-175034/>. Acessado em: 12 maio 2016.

CASTELLS, M. A sociedade em rede. 5. ed. São Paulo: Paz e Terra, 1999.

CHARLOT, B. Da relação como saber: elementos para uma teoria. Porto Alegre: Artmed, 2000.

ERICSON. Ericson mobility report. Stockholm, 2015. Disponível em: <http://www. ericsson.com/res/docs/2015/mobility-report/ericsson-mobility-report-nov-2015>. Acesso em: 22 abr. 2016

LEMOS, A. Inclusão digital: polêmica contemporânea. Salvador: EDUFBA, 2011.

LÉVY, P. Cibercultura. São Paulo: Ed.34, 1999.

LÉVY, P. A inteligência coletiva: por uma Antropologia do ciberespaço. São Paulo: Loyola, 1998.

MONTEIL, J. M. Dynamique sociale et systèmes de formation. Paris: Editions Universitaires, 1985.

MOREIRA, M. A. Teorias de aprendizagem: cognitivismo, humanismo, comportamentalismo. São Paulo: Ed. EPU, 1999.

NAÇÕES UNIDAS. ONU: 4,4 bilhões de pessoas permanecem sem acesso à internet. Brasília, DF, 7 out. 2013. Disponível em: <https://nacoesunidas.org/onu-44-bilhoesde-pessoas-permanecem-sem-acesso-a-internet/>. Acesso em: 22 abr. 2016. 
ONG, W. J. Oralidade e cultura escrita: a tecnologização da palavra. São Paulo: Papirus, 1998.

PODEMOS vencer a exclusão digital. Nova Escola, São Paulo, 2005. Disponível em: <http://revistaescola.abril.com.br/politicas-publicas/planejamento-efinanciamento/podemos-vencer-exclusao-digital-425469.shtml>. Acesso em: 10 abr. 2016.

POPULAÇÃO mundial vai crescer 53\% e chegar a 11,2 bilhões em 2100, diz relatório da ONU. 0 Globo, Rio de Janeiro, 30 jul. 2015. Disponível em: <http:// oglobo.globo.com/sociedade/sustentabilidade/populacao-mundial-vai-crescer-53chegar-112-bilhoes-em-2100-diz-relatorio-da-onu-17003177>. Acesso em: 26 abr. 2016.

ROGERS, C. R. Freedom to learn. Columbus: Ch. E. Merril, 1969.

SASSAKI, R. K. Inclusão: construindo uma sociedade para todos. Rio de Janeiro: WVA, 1997.

SILVA, H. et al. Inclusão digital e educação para a competência informacional: uma questão de ética e cidadania. Ciência da Informação, Brasília, DF, v. 34, n. 1, p. 2836, jan./abr. 2005.

SMAAL, B. Pesquisadores estimam a quantidade de informação existente no mundo. [S.I.]: Tecmundo, 16 fev. 2011. Disponível em: <http://www.tecmundo. com.br/curiosidade/8567-pesquisadores-estimam-a-quantidade-de-informacaoexistente-no-mundo.htm>. Acesso em: 4 abr. 2016.

UNESCO. 2015 International Year of Light: about the year of light. Paris, 2015. Disponível em: <http://www.light2015.org/Home/About.html>. Acesso em: 19 abr. 2016.

WARSCHAUER, M. Tecnologia e inclusão social: a exclusão digital em debates. São Paulo: Ed. Senac São Paulo, 2006. INCLUSÃO DIGITAL E EDUCAÇÃO: UMA LENTA CONEXÃO. 